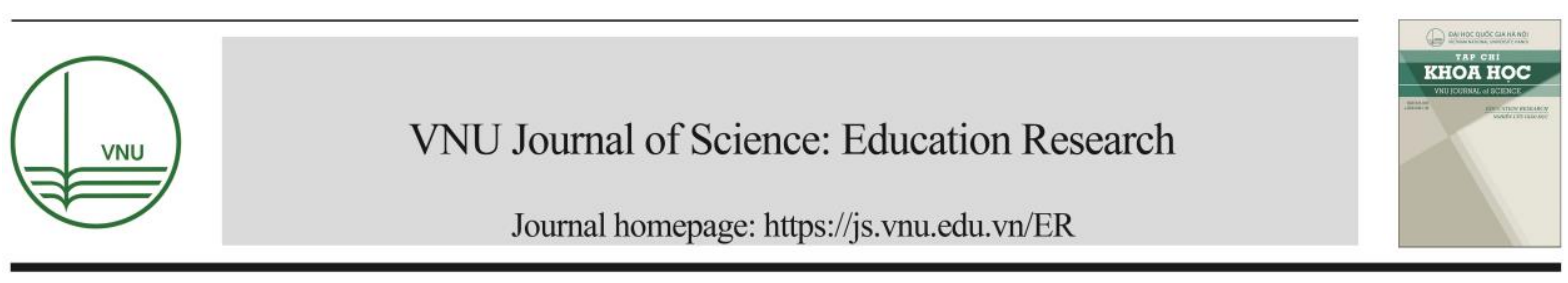

\title{
Review Article \\ Innovation Approaches in Vietnam and Thailand Higher Education Institutions
}

\author{
Nguyen Huu Thanh Chung 1,*, Tran Van Hai ${ }^{1}$, Luu Quoc Dat ${ }^{2}$, Nguyen Huu Duc ${ }^{3,4}$ \\ ${ }^{1}$ VNU University of Social Sciences and Humanities, 336 Nguyen Trai, Hanoi, Vietnam \\ ${ }^{2}$ VNU University of Economics, 144 Xuan Thuy, Cau Giay, Hanoi, Vietnam \\ ${ }^{3}$ Vietnam National University, Hanoi, 144 Xuan Thuy, Cau Giay, Hanoi, Vietnam \\ ${ }^{4}$ UPM Innovation Institute, 144 Xuan Thuy, Cau Giay, Hanoi, Vietnam
}

Received 25 November 2021

Revised 06 January 2022; Accepted 06 January 2022

\begin{abstract}
In the $4^{\text {th }}$ industrial revolution era, instead of following the entrepreneurial approach of traditional third-generation universities, nowadays, a university is redefined as an ecosystem that innovates not only "for itself" but also "for others". Thus, university transformation is described with three key characteristics: radical mindset changes, holistic innovation facilitation, and ecological and social norm encouragement. It responds well to the demands of entrepreneurial spirit, innovative approaches, digital transformation, personalized education, and ecological and social norm promotion. The responsiveness to this university model can be assessed by the criteria and indicators of the new rating system of the University Performance Metrics (UPM). Practically, UPM has been applied to benchmark the universities of Vietnam and Thailand. The results indicate that while facilitating the research quality focus, higher education institutions need to develop the innovation-driven university model, supporting the universities' autonomy in implementing their activities.
\end{abstract}

Keywords: Third generation university, innovation deriven university, ecological university, digital transformation, university rating, Vietnam universities, Thailand universities.

\footnotetext{
${ }^{*}$ Corresponding author.

E-mail address: chungnht@gmail.com

https://doi.org/10.25073/2588-1159/vnuer.4613
} 


\title{
Mức độ tiếp cận đổi mới sáng tạo của các trường đại học Việt Nam và Thái Lan
}

\author{
Nguyễn Hữu Thành Chung 1,*, Trần Văn Hải ${ }^{1}$, Lưu Quốc Đạt ${ }^{2}$, Nguyễn Hữu Đức ${ }^{3,4}$ \\ ${ }^{1}$ Trường Đại học Khoa học Xã hội và Nhân văn, \\ Đại học Quốc gia Hà Nội, 336 Nguyễn Trãi, Hà Nội, Việt Nam \\ ${ }^{2}$ Trường Đại học Kinh tế, Đại học Quốc gia Hà Nội, 144 Xuân Thủy, Cầu Giấy, Hà Nội, Việt Nam \\ ${ }^{3}$ Đại hoc Quốc gia Hà Nọii, 144 Xuân Thủy, Cầu Giấy, Hà Nội, Việt Nam \\ ${ }^{4}$ Viện Đổi mói sáng tạo UPM, 144 Xuân Thủy, Cầu Giấy, Hà Nội, Việt Nam
}

Nhận ngày 26 tháng 11 năm 2021

Chỉnh sửa ngày 06 tháng 01 năm 2022; Chấp nhận đăng ngày 06 tháng 01 năm 2022

\begin{abstract}
Tóm tắt: Trong thời đại cách mạng công nghiệp lần thứ tư (CMCN 4.0), thay vì cách tiếp cận khởi nghiệp sáng tạo của thế hệ đại học thứ ba truyền thống, các trường đại học cần được định nghĩa lại như một hệ sinh thái đổi mới sáng tạo (ĐMST) không phải chỉ vì lợi ích "cho chính nó" mà còn phải "cho những người khác", vì cộng đồng. Do đó, quá trình chuyển đổi trường đại học cần đảm bảo cả ba yêu cầu: thay đổi căn bản tư duy, triển khai ĐMST toàn diện, cũng như khuyến khích các chuẩn mực về sinh thái và xã hội. Quá trình đổi mới như vậy tích hợp được cả tinh thần khởi nghiệp, tiếp cận đổi mới sáng tạo, chuyển đổi số, đào tạo cá thể hóa cũng như thúc đẩy các chuẩn mực đạo đức mới. Mức độ đáp ứng mô hình đại học đó có thể được đánh giá dựa trên các tiêu chuẩn và chỉ báo của hệ thống đối sánh chất lượng giáo dục đại học (University Performance Metrics - UPM). Trong công trình nghiên cứu này, bộ tiêu chí UPM được áp dụng để đối sánh cho một số trường đại học của Việt Nam và Thái Lan. Kết quả chỉ ra rằng, trong khi phải tập trung nâng cao hơn nữa chất lượng các nghiên cứu cơ bản, các cơ sở giáo dục đại học (CSGDĐH) cần phát triển toàn diện theo mô hình đại học theo định hướng ĐHST. Đấy cũng là cơ sở để các trường đại học tăng cường năng lực và các điều kiện thực hiện đầy đủ quyền tự chủ trong lộ trình triển khai sứ mệnh của mình.
\end{abstract}

Tù khóa: Đại học thế hệ thứ ba, Đại học định hướng đổi mới sáng tạo, Hệ sinh thái đại học, Chuyển đổi số, Xếp hạng đối sánh, Đại học Việt Nam, Đại học Thái Lan.

\section{Mở đầu}

Cách mạng công nghiệp lần thứ tư $(\mathrm{CMCN}$ 4.0) đang đặt ra những thách thức lớn cho các CSGDĐH phải thay đổi để đáp ứng những yêu cầu mới [1-6]. Khi đó, không những mô hình đại học cần phải được định nghĩa lại mà các bộ công cụ đối sánh chất lượng tương ứng cũng phải được phát triển, đảm bảo khả năng phản ánh đầy đủ các đặc trưng và yêu cầu mới và hỗ trợ hiệu quả các cơ CSGDĐH quản trị quá trình chuyển đổi phù hợp với bối cảnh của đất nước và khu vực. Gần đây, chúng tôi đã đề xuất và

\footnotetext{
* Tác giả liên hệ.

Địa chỉemail: chungnht@gmail.com

https://doi.org/10.25073/2588-1159/vnuer.4613
}

phát triển một hệ thống đánh giá mới - hệ thống xếp hạng đối sánh chất lượng giáo dục đại học UPM [7] để đánh giá khả năng đáp ứng của các trường đại học trong kỷ nguyên $\mathrm{CMCN}$ 4.0. Mục tiêu chính của hệ thống xếp hạng đối sánh này là thúc đẩy sự đối sánh giữa các CSGDĐH theo năm đặc trưng cốt lõi của giáo dục 4.0. Đó là tinh thần khởi nghiệp, tiếp cận ĐMST, chuyển đổi số, đào tạo cá thể hóa và hệ sinh thái đại học. Hiện tại, hơn 50 trường đại học ở khu vực Châu Á (Brunei Darussalam, Myanmar, Indonesia, Philippines, Thái Lan, Việt Nam và Đài Loan) đã tham gia hệ thống này.

Trong công trình nghiên cứu này, chúng tôi khái quát hóa lại các đặc trưng của đại học 4.0 theo cách tiếp cận của UPM về mô hình đại học 
định hướng ĐMST, đồng thời sử dụng các tiêu chuẩn/chỉ báo cốt lõi và dữ liệu của hệ thống UPM để đánh giá mức độ tiếp cận ĐMST nói riêng và $\mathrm{CMCN} 4.0$ nói chung của một số CSGDĐH của Việt Nam và Thái Lan. Trên cơ sở đó, một số gợi ý về định hướng phát triển của đại học Việt Nam được đề xuất.

\section{Quan niệm lại mô hình đại học hiện đại}

Trong thập kỷ qua, bên cạnh các tác động về một tương lai bất định do $\mathrm{CMCN} 4.0$ mang tới, các CSGDĐH còn phải đối mặt với việc cắt giảm tài chính công và nguy cơ mất cân bằng giữa tự chủ tài chính và các tiến bộ văn hóa, xã hội và môi trường. Để khắc phục các bất cập nêu trên, không những cần phải có tầm nhìn xa, mà các trường đại học còn cần phải vượt qua những suy nghĩ hạn hẹp và thực dụng trong các hoạt động hướng nội của mình, hướng đến bức tranh toàn cảnh để xác định mô hình đại học phù hợp nhất đối với bối cảnh hiện nay. Trong trường hợp này, hãy cùng nhìn lại lịch sử phát triển của các thế hệ đại học và xác định lại các đặc trưng cần thiết để điều chỉnh các hoạt động, đảm bảo sự hài hòa với các hệ sinh thái mới, đồng thời hỗ trợ và nuôi dưỡng sự phát triển của hệ sinh thái đó. Đây là phương pháp mà hệ thống xếp hạng đối sánh UPM đã tiếp cận [7].

\subsection{Tóm lược về lịch sủ phát triển các thế hệ đại học thế giới}

Trong khi vẫn còn có nhiều ẩn dụ, người ta vẫn có thể nói rằng các trường đại học thế giới đã trải qua những thay đổi mang tính cách mạng để đáp ứng các xu hướng thay đổi trong lịch sử phát triển gần 1000 năm qua với ba thế hệ đại học (Generation University - GU) [2].

Theo tài liệu của Wissema [2], các trường đại học thế hệ đầu tiên (1GU) là các trường đại học siêu hình, phụng sự Chúa, xuất hiện lần đầu vào thời trung cổ (tức là Đại học Paris - năm 1200 hoặc thậm chí trước đó là Đại học Bologne - năm 1088). Vào thời điểm đó, trường đại học là những nhà thờ, tu viện, chủ yếu giảng dạy với phương pháp thuyết trình một chiều bằng ngôn ngữ Latinh cùng với bảng và phấn. Các trường đại học này chỉ tập trung củng cố các chân lý phổ quát và đào tạo các nhà lãnh đạo tương lai cho xã hội đương thời. Tuy nhiên, trong thời kỳ này nền giáo dục khai phóng đã được hình thành.

Trong thời đại phát triển hơn, các trường đại học thế hệ thứ hai (2GU) được xác định là trường đại học định hướng nghiên cứu xuất hiện trong thời đại hậu công nghiệp (tức là Đại học Humboldt Berlin - năm 1810). Theo đó mối quan tâm của các trường đại học đối với các chân lý phổ quát nói trên đã giảm để tập trung vào các nghiên cứu thực nghiệm và các lý thuyết lôgic với cách tiếp cận đơn ngành, thậm chí chuyên môn hóa rất hẹp và sâu. Mặc dù đã có sự tương tác hai chiều giữa giảng viên với sinh viên, nhưng chức năng chính của đại học $2 \mathrm{GU}$ vẫn là truyền thụ kiến thức và nghiên cứu cơ bản. Trong kỷ nguyên $2 \mathrm{GU}$, kết quả nghiên cứu trong các trường đại học là một nguồn tri thức quan trọng để phát triển ĐMST, nhưng các trường chỉ mong rằng bằng cách nào đó tìm được người có thể ứng dụng các kết quả đó một cách hữu ích, còn các nhà khoa học không hề bận tâm. Trong khi đó, Chính phủ các nước, một mặt hài lòng với hoạt động nghiên cứu khoa học và đào tạo của trường đại học, mặt khác vẫn có mong muốn rằng các trường đại học là các vườn ươm có khả năng thương mại hóa các kết quả nghiên cứu khoa học và công nghệ mới dưới hình thức các công ty hoặc công ty khởi nghiệp [2]. Do đó, Chính phủ yêu cầu và đồng thời tăng cường cấp ngân quỹ để các trường đại học quan tâm và tích cực khai phá các tri thức mới đã sáng tạo ra. Nhờ vậy, các trường đại học đã trở thành lực lượng có đóng góp trực tiếp vào tăng trưởng kinh tế. Theo đó, các trường đại học thế hệ thứ ba $(3 \mathrm{GU})$ đã ra đời với sứ mệnh mới của mình.

Đại học 3GU có thể được coi là trường đại học định hướng cả sáng tạo tri thức và khai phá tri thức, đóng góp tích cực việc tạo ra giá trị cho xã hội thông qua việc hỗ trợ các nhà khởi nghiệp công nghệ và các công ty khởi nghiệp. Khai thác bí quyết trở thành mục tiêu thứ ba của trường đại học và các trường đại học được coi là cái nôi của hoạt động khởi nghiệp mới bên cạnh các nhiệm vụ truyền thống là đào tạo và nghiên cứu. Trong trường hợp này, sản phẩm 
của các trường đại học tạo ra không chỉ có các nhà khoa học và các nhà công nghệ, mà còn cả các nhà khởi nghiệp.

\subsection{Xu thế phát triển của đại học hiện đại}

Các trường đại học định hướng khai phá tri thức (entrepreneuprial university hay knowledge exploited universities) 3GU mô tả trên đây tập trung hoạt động như một vườn ươm tự nhiên, kiến tạo các điều kiện để hỗ trợ cho giảng viên và sinh viên tiếp cận các hoạt động khởi nghiệp, từ các phát minh, đến việc thương mại hóa và các kết nối với các bên liên quan cần thiết [8]. Đó dường như chỉ là sứ mệnh và khả năng thực hiện của các trường đại học nghiên cứu xuất sắc $(2 \mathrm{GU})$. Thực tế không phải như vậy, quá trình phát triển tới đại học $3 \mathrm{GU}$ nên được khuyến khích đối với tất cả các CSGDĐH theo định hướng nghiên cứu (2GU) lẫn định hướng ứng dụng (1GU). Vì vậy, mô hình trường đại học cũng như quy trình triển khai phát triển nó cũng cần được làm rõ thêm. Thêm vào đó, hoạt động của trường đại học định hướng khai phá tri thức được coi là một mô hình đại học "vì bản thân" [3]. Mặc dù đã có triển khai các hoạt động phục vụ cộng đồng khá đa dạng, nhưng trước hết và sau cùng, các trường đại học này quan tâm nhiều đến việc tối ưu hóa lợi ích riêng và tập trung quá nhiều vào các khía cạnh kinh tế. Hơn nữa, $\mathrm{CMCN} 4.0$ đã và đang thay đổi cách loài người sống, làm việc và quan hệ, tương tác với nhau. Sự thay đổi nhanh chóng của các công nghệ và kỹ thuật số đang cho thấy các phương thức tiếp cận truyền thống của các trường đại học đã lỗi thời và yêu cầu một mô hình mới.

Nói cách khác, trong kỷ nguyên CMCN 4.0, giáo dục đại học đang đối mặt với một tương lai bất định với những xu thế sau đây [9]:

i) Xu thế thay đổi việc làm và thị trường lao động: các công việc đang tồn tại có thể sẽ lỗi thời trong tương lai và các loại công việc mới sẽ xuất hiện; các mẫu hình công việc, dự án ngắn hạn hoặc bán thời gian trở nên phổ biến. Năng lực học tập suốt đời trở nên cần thiết;

ii) Xu thế phát triển công nghệ: tuổi thọ của các công nghệ giảm theo cấp số nhân, các công nghệ mới lại xuất hiện nhanh, đòi hỏi phải luôn có sự dự đoán và chuẩn bị các kỹ năng và kiến thức mới, đặc biệt là kiến thức và kỹ năng số;

iii) Cơ hội khởi nghiệp sáng tạo cho mọi người, mọi lĩnh vực và mọi quốc gia: nền tảng và hạ tầng cồng nghệ có tính phổ cập và toàn cầu hóa cao đã được tạo thuận lợi cho cơ hội khởi nghiệp nhỏ và siêu nhỏ với số vốn đầu tư ban đầu không lớn, không cần tư liệu sản xuất và lực lượng lao động nhưng lợi nhuận thu về cao, chỉ cần có kiến thức và kỹ năng khởi nghiệp;

iv) Xu thế thay đổi nhu cầu: thay đổi cách con người sống, làm việc và quan hệ với nhau, cần thiết phải thay đổi các mô hình trong việc giải quyết các yêu cầu mới. Học tập theo đam mê và đào tạo cá thể hóa trở thành một đặc trưng chủ đạo;

v) Xu thế thay đổi hệ thống các giá trị: các cuộc cách mạng công nghiệp chỉ tập trung vào những cải tiến khoa học và do đó dẫn đến sự phá vỡ hệ thống giá trị tinh thần. Các năng lực nhân văn như trí thông minh xúc cảm, quan tâm, thấu cảm và trách nhiệm xã hội cần thiết được nuôi dưỡng ở mọi giai đoạn học tập. Do đó, giáo dục định hướng và thúc đẩy giá trị xã hội là yếu tố quan trọng để tạo ra những sinh viên tốt nghiệp cân bằng, những người sau này sẽ trở thành thành viên đạo đức của xã hội.

Trong bối cảnh này, quá trình chuyển đổi đại học cần diễn ra theo ba định hướng chính: thay đổi căn bản tư duy, phát triển toàn diện ĐMST và thúc đẩy các hệ sinh thái đại học với chuẩn mực xã hội theo mô hình đại học định hướng ĐMST. Mô hình đại học này không chỉ đáp ứng tốt $\mathrm{xu}$ hướng của đại học $3 \mathrm{GU}$ và CMCN 4.0 mà còn là sự thích ứng tốt cho hầu hết các trường đại học trong thời kỳ hiện đại.

Thay đổi căn bản tư duy

Hầu hết các quốc gia trên thế giới đều mong muốn thịnh vượng, nhưng họ vẫn gặp nhiều khó khăn với hệ thống giáo dục đại học của mình, đặc biệt là thế hệ đại học $2 \mathrm{GU}$ không được đổi mới, mà vẫn tiếp tục truyền thống đào tạo nguồn nhân lực và nghiên cứu cơ bản, chưa quan tâm đến việc sử dụng và khai phá tri thức đã được tạo ra. Lưu ý rằng, việc tăng cường tư duy và hành vi khởi nghiệp của sinh viên ở các CSGDĐH Hoa Kỳ (sau chiến tranh thế giới thứ hai) và ở các CSGDĐH ở Châu Âu (vào cuối 
thế kỷ 20) đã được tổng kết như là "sự thay đổi tư duy" lần thứ nhất của trường đại học [10] và được coi là những động lực quan trọng cho sự phát triển nền kinh tế quốc gia và thế giới. Mới đây, ngày 22/7/2021, Vương quốc Anh vừa ban hành Chiến lược ĐMST (UK Innovation Strategy) [11]. Đây như là công cuộc ĐMST lần thứ hai để vừa giải quyết các khó khăn sau khi rời khỏi cộng đồng châu Âu, chịu tác động của đại dịch COVID-19, tham gia cuộc cạnh tranh ĐMST toàn cầu để trở thành trung tâm ĐMST toàn cầu vào năm 2035.

Bên cạnh tư duy khởi nghiệp, tư duy và kỹ năng số (hoặc thậm chí là tư duy máy tính) là thay đổi căn bản thứ hai của các trường đại học trong kỷ nguyên CMCN 4.0 này. Kỹ năng số liên quan nhiều đến cả công nghệ và con người. Trong thời đại kỹ thuật số, thành công chính là sự kêt hợp hài hòa con người và công nghệ với nhau. Do đó, tư duy số là một yếu tố quan trọng, cần thiết để tích hợp công nghệ vào các hoạt động hàng ngày và chiết xuất giá trị từ sự tích hợp đó. Đặc biệt, tư duy số không chỉ đơn thuần là khả năng sử dụng công nghệ, mà đúng hơn, nó là sự tích hợp cả thái độ và hành vi cho phép mọi người và các tổ chức đoán nhận, dự báo được các khả năng tương lai.

Đối với các nước phát triển, sự thay đổi về tư duy khởi nghiệp và chuyển đổi số diễn ra khi các nước này đã có văn hóa và trải nghiệm về các vấn đề đó. Riêng đối với các nước đang phát triển, đặc biệt như Việt Nam, sự thay đồi đó hoàn toàn mới mẻ, rất căn bản và sâu sắc.

Phát triển toàn diên ĐMST

ĐMST không chỉ giới hạn trong lĩnh vực nghiên cứu và triển khai $(\mathrm{R} \& \mathrm{D})$, không chỉ là việc giới thiệu thành công một sản phẩm mới nào đó dựa trên một phát minh hoặc ứng dụng, mà còn là khả năng nhận biết và nắm bắt cơ hội, tạo ra cơ hội, chấp nhận rủi ro và vượt qua thách thức [12], tìm được giải pháp phù hợp để tạo ra một sản phẩm mới, giải pháp mới, dịch vụ mới, thâm chí là sự thay đổi về mô hình tổ chức để đạt được sự phát triển tối ưu cho tương lai [13]. Đấy không chỉ giới hạn bởi các cơ chế công nghệ đẩy, thị trường kéo đơn thuần nữa. ĐMST phải được thực hiện một cách toàn diện phải bao gồm cả về lãnh đạo và quản trị; hệ sinh thái; con người và động lực; hoạt động dạy và học; nghiên cứu khai phá tri thức,.. Trong đó, hoạt động đào tạo dựa vào nghiên cứu và ĐMST, đồng thời các chương trình bồi dưỡng kỹ năng và tư duy ĐMST cho người học và cộng đồng nói chung sẽ góp phần thực thi trực tiếp hành trình ĐMST của quốc gia. Trong trường hợp này, nhiều quốc gia đã áp dụng các mô hình đào tạo khai phóng (liberal arts) kết hợp với tư duy thiết kế (design thinking) rất hiệu quả.

\section{Hệ sinh thái và các chuẩn mục xã họi}

Trường đại học của thế kỷ 21 được đặt trong và có liên kết với môi trường xã hội, văn hóa và cả môi trường vật chất của hệ sinh thái theo nhiều chiều cạnh khác nhau. Trường đại học phải có vai trò áp dụng triết lý và các chuẩn mực của hệ sinh thái để dẫn dắt, củng cố và nâng cao các mối quan hệ phức tạp này. Trong trường hợp này, hệ sinh thái đại học sẽ vận hành vì "mọi người", nhưng ở đây, "mọi người" phải được hiểu theo cách rộng nhất có thể của hệ sinh thái. Trước hết, khái niệm "trường đại học vì mọi người" có đặc trưng hướng ngoại, kết nối chặt chẽ với doanh nghiệp và cộng đồng xung quanh, phục vụ hiệu quả nhu cầu học tập của sinh viên [3]. Theo cách tiếp cận đơn giản hơn, hệ sinh thái đại học có thể được liên hệ với ý tưởng về sự phát triển bền vững của trường đại học và ngược lại, trường đại học cần có trách nhiệm hỗ trợ sự phát triển của các hệ sinh thái đó, trong đó các mục tiêu phát triển bền vững của Liên Hợp Quốc nên được áp dụng. Ngoài ra, các hoạt động gắn kết cộng đồng nhằm thúc đẩy tác động của trường đại học đối với sự phát triển bền vững của cộng đồng (như biến đổi khí hậu, chương trình tiết kiệm năng lượng, chương trình bảo tồn nước, chương trình tái chế, chính sách giao thông vận tải) và thúc đẩy hài hòa các chuẩn mực xã hội (như các hoạt động đền bù, hỗ trợ học sinh có hoàn cảnh khó khăn, giúp đỡ người nghèo, người bị thiên tai) cần được tạo điều kiện. Ngoài ra, trong thời đại kỹ thuật số, đạo đức thông tin, bao gồm tính trung thực trong học tập, các hành vi đạo đức, các biện pháp bảo mật điện tử cần phải được đảm bảo. 


\section{Mô hình đại học đổi mới sáng tạo}

Trên cơ sở tích hợp các thảo luận ở trên về tinh thần khởi nghiệp, tư duy ĐMST, kỹ năng số, đào tạo cá thể hoá, các chuẩn mực sinh thái và xã hội đối với các trường đại học hiện đại, có thể đề xuất mô hình đại học định hướng ĐMST (nhóm 3 như trong Hình 1. Đây là mô hình đại học vừa thích ứng khá đầy đủ với các yêu cầu của $\mathrm{CMCN} 4.0$, và đặc biệt vừa có tính hướng đích chung và phổ quát cho tất cả các loại hình CSGDĐH (định hướng ứng dụng, nhóm 1 hay $1 \mathrm{GU}$ và định hướng nghiên cứu, nhóm 2 hay $2 \mathrm{GU}$ ) cùng phát triển hướng đến nhóm 3 (hay $3 \mathrm{GU}$ phổ quát) để đáp ứng môi trường bất định hiện nay (Hình 1). Theo mô hình này, các CSGDĐH nhóm 2 có thể không quan tâm đến ĐMST để phát triển lên đại học nhóm 4 . Tuy nhiên, đây là cách đầu tư quá vì khoa học, không phù hợp với mục tiêu phát triển của nhiều quốc gia. Mô hình đại học đẳng cấp thế giới mô tả cho nhóm 5 là mô hình tích hợp của nhóm 2 và nhóm 3 - cả đào tạo, nghiên cứu và thương mại hóa đều xuất sắc.

Mô hình đại học ĐMST (nhóm 3) này bao gồm hai tầng chính (tầng nền tảng về đào tạo và nghiên cứu truyền thống và tầng $Đ M S T$ phổ quát) và hai thành tố $Đ M S T$ đặc thù tùy chọn (tức là ĐMST đặc thù tương ứng với đại học định hướng nghiên cứu và ứng dụng) (Hình 2).

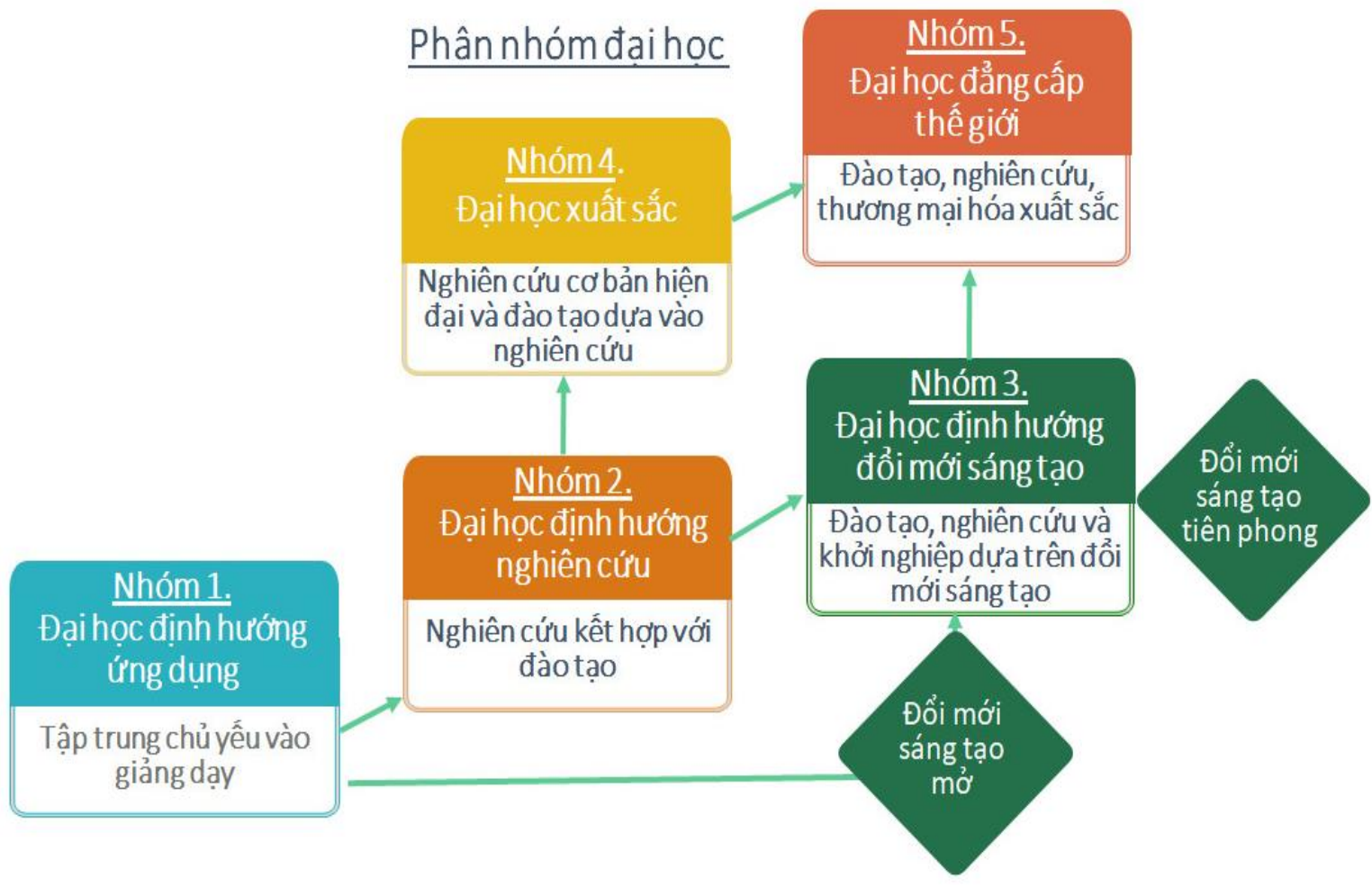

Hình 1. Phân loại trường đại học và sự chuyển đổi của các trường đại học định hướng nghiên cứu (nhóm 2) và định hướng ứng dụng (nhóm 1) sang mô hình đại học định hướng ĐMST [2].

Tầng đào tạo và nghiên cứu truyền thống bao gồm các thành tố chức năng cơ bản của đại học truyền thống thực thi các nhiệm vụ đào tạo và nghiên cứu cơ bản (các khoa, bộ môn, hệ thống phục vụ giảng dạy và học tập,...). Điều này đã quá quen thuộc, nên sẽ không trình bày chi tiết trong nghiên cứu này. Dưới đây, các khía cạnh khác nhau của tầng $Đ M S T$ phố quát và hai thành tố $Đ M S T$ đặc thù sẽ được trình bày. 
ĐĀI HỌC ĐỊNH HƯỚNG ĐỔI MỚl SÁNG TAO

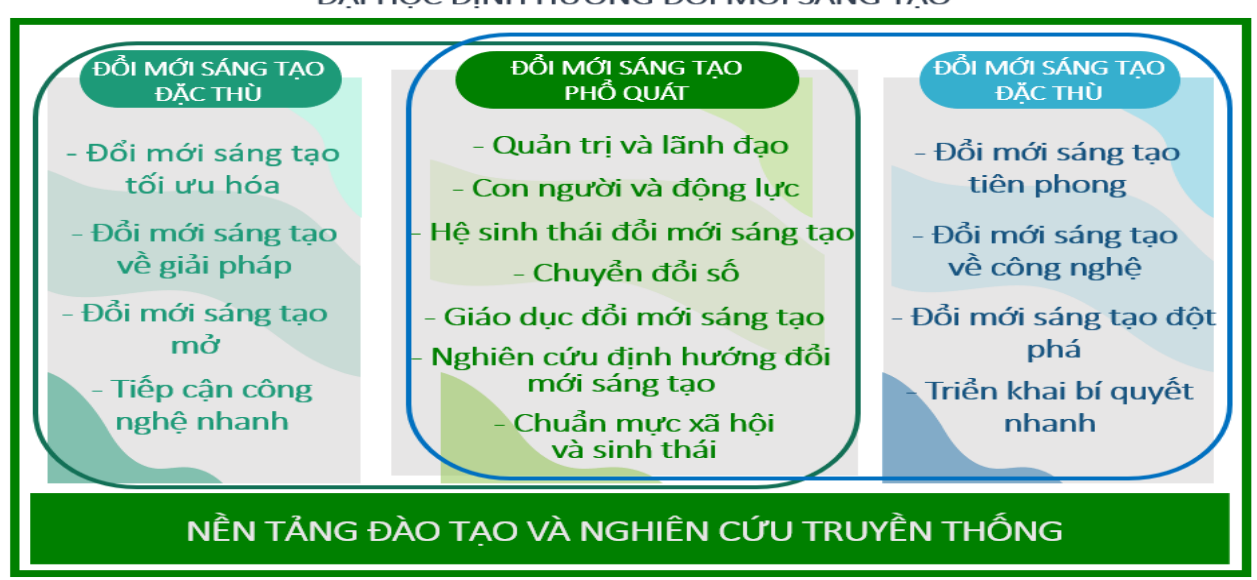

ĐẠ HOC ĐỊNH HƯớNG ỨNG DỤNG

ĐẠI HOC ĐINHH HƯỚNG NGHIÊN CỨU

Hình 2. Mô hình đại học ĐMST.

\subsection{Tầng đổi mói sáng tạo phổ quát}

Tầng ĐMST phổ quát bao gồm bảy thành phần sau.

\section{Quản trị và lãnh đạo}

Theo mô hình đại học ĐMST, tinh thần khởi nghiệp, tư duy ĐMST, chuyển đổi số, đào tạo cá thể hóa và thúc đẩy các chuẩn mực xã hội là những nội dung chính của chiến lược phát triển, đòi hỏi phải có sự cam kết từ lãnh đạo cấp cao và phải trở thành văn hóa đại học. Đại học phải xây dựng được mô hình tổ chức, trong đó hoạt động khởi nghiệp được lồng ghép và phối hợp ở tất cả các cấp từ lãnh đạo trường đến bộ môn, từ giảng viên, cán bộ phục vụ đến sinh viên,... Quyết tâm đó cũng phải được tuyên bố trong kế hoạch chiến lược và giá trị cốt lõi của CSGDĐH, đồng thời phải được tích hợp vào cơ chế đảm bảo chất lượng của tất cả các bộ phận học thuật và phục vụ của trường. Hơn thế nữa, để tăng tính khả thi, cần có đủ hệ thống các văn bản, chính sách và phân bổ nguồn lực để thực hiện sứ mệnh và đạt được các mục tiêu đã được thiết lập, đặc biệt là chính sách đầu tư nguồn lực để đạt được các mục tiêu của đại học định hướng ĐMST.

Con nguời và động lục

Trường đại học đầu tư vào chiến lược phát triển nhân tài để hỗ trợ chương trình ĐMST, đặc biệt là phát triển đội ngũ giảng viên và thu hút sinh viên, nâng cao nhận thức về tầm quan trọng của việc phát triển tư duy ĐMST của cả giảng viên và sinh viên. Trường đại học tích cực khuyến khích các cá nhân nêu cao và thực thi tinh thần khởi nghiệp, hỗ trợ và kiến tạo các điều kiện cho các nhà khoa học và sinh viên triển khai được ý tưởng khởi nghiệp thành hành động. Bên cạnh việc tạo ra các cơ chế và phương thức để phá bỏ các ranh giới cát cứ truyền thống và thúc đẩy các mối quan hệ mới, gắn kết các bên liên quan trong trường (giảng viên và sinh viên) lại với nhau, trường đại học còn phải tạo cơ chế và chính sách khuyến khích đối với các đối tác bên ngoài để cùng đóng góp vào chiến lược ĐMST của trường đại học.

\section{Hê sinh thái ĐMST}

Bên cạnh cơ cấu tổ chức và cơ sở vật chất phục vụ cho hoạt động đào tạo và nghiên cứu cơ bản truyền thống, hệ sinh thái đại học ĐMST cần có sự mở rộng hơn rất nhiều cả về cơ cấu và chức năng. Trước hết, các trung tâm nghiên cứu liên ngành hoạt động thông qua các dự án, hướng tới mục tiêu chuyển giao tri thức và công nghệ cho các doanh nghiệp cần phải được hình thành. Ngoài ra, không gian sáng tạo, hỗ trợ khởi nghiệp và ĐMST cũng cần phải được thiết lập để cán bộ giảng viên, sinh viên và cộng 
đồng khởi nghiệp chia sẻ ý tưởng, thiết kế, xây dựng và phát triển sản phẩm mới. Bên cạnh vườn ươm doanh nghiệp và trung tâm khởi nghiệp, trung tâm phát triển tài sản trí tuệ là một bộ phận không thể thiếu nếu như đại học quan tâm đến việc gia tăng giá trị cho xã hội.

Ý nghĩa sinh thái của CSGDĐH được hiểu rất rộng và có thể triển khai theo các mô hình rất đa dạng, nhưng những nội dung cơ bản và cụ thể nhất liên quan đến hình thái của khuôn viên đại học mở, thân thiện và hiện đại. Trong hệ sinh thái này, trường đại học có mối liên kêt chặt chẽ với các vườn ươm, công viên khoa học và các đối tác bên ngoài khác, tạo cơ hội trao đổi kiến thức và các ý tưởng, tư duy thiết kế. Đặc trưng này giúp đại học định hướng ĐMST không những có thêm các nguồn lực vật chất mà còn phát triển được môi trường tự do học thuật, thúc đẩy sáng tạo cho tất cả các bên liên quan. Cuối cùng nhưng không kém phần quan trọng, ý nghĩa sinh thái của trường đại học còn liên quan trực tiếp đến mục tiêu phát triển bền vững của trường cũng như của cộng đồng. Trong trường hợp này, các trường đại học cũng được khuyến khích thực hiện các mục tiêu phát triển bền vững của Liên Hợp Quốc đề ra.

Chuyển đổi số

Chuyển đổi số không chỉ đơn giản là quá trình số hóa thông thường mà là sự chuyển đổi sâu sắc mô hình và phương thức hoạt động và tổ chức sản xuất. Chuyển đổi số trong giáo dục đại học có thể được coi là việc xây dựng và phát triển mô hình đại học thông minh. Dựa vào sáng kiến quốc gia của Hàn Quốc về giáo dục thông minh [13], gần đây, chúng tôi đã đề xuất mô hình khái niệm về trường đại học thông minh "là một cơ sở giáo dục định hướng ĐMST được chuyển đổi số; sử dụng hạ tầng số (pháp lý số, nhân lực số, dữ liệu số, công nghệ số và ứng dụng số) để cung cấp dịch vụ đào tạo cá thể hóa cho người học mọi thế hệ ở trong nước và trên khắp thế giới, đáp ứng yêu cầu học tập suốt đời và phát triển bền vững của các cá nhân cũng như các quốc gia" [14]. Đại học thông minh bao gồm 6 thành tố cơ bản là tài nguyên số, học liệu truy cập mở, môi trường học tập ảo, giáo dục cá thể hóa, học tập có tương tác và nền tảng kỹ thuật số. Các thành tố này kết hợp với nhau trong ba trụ cột là số hóa, mô hình dạy-học số và quá trình chuyển đổi số căn bản toàn diện của tổ chức.

Chuyển đổi số đóng vai trò quan trọng trong xã hội phát triển hiện đại, đặc biệt trong giáo dục, chuyển đổi số có thể hỗ trợ cho việc học tập linh hoạt, theo kế hoạch và năng lực của từng cá nhân, đồng thời tạo cơ hội để vượt qua thách thức theo những cách mới và mở ra các cơ hội trước đây chưa từng có [6]. Vai trò của chuyển đổi số trong đại dịch COVID-19 hiện nay là một ví dụ thuyết phục. Để định hướng cho việc áp dụng chuyển đổi số và đồng thời đánh giá tác động của chuyển đổi số trong CSGDĐH, hệ thống đối sánh chất lượng giáo dục đại học UPM đã đưa ra 8 tiêu chí, đồng thời là 8 quy trình và nội dung cơ bản cần thực hiện, bao gồm: khả năng phân tích và quản lý thông tin; mức độ phong phú của tài nguyên số; tần suất sử dụng tài nguyên số; mức độ tương tác trong dạy-học trực tuyến; số lượng các bài giảng điện tử, khả năng tổ chức dạy-học kết hợp; việc ứng dụng hệ thống thực ảo (CPS) trong dạy và học và cuối cùng là các vấn đề đạo đức thông tin [7].

\section{Giáo duc ĐMST}

Trước hết, tư duy khởi nghiệp và ĐMST phải được xác định và mô tả trong chuẩn đầu ra của các chương trình đào tạo, đồng thời triết lý giáo dục đó được phản ánh trong các hoạt động dạy và học. Phương pháp kiểm tra, đánh giá phải tương thích với tư duy và triết lý giáo dục mới. Trong trường hợp này, các trường đại học ĐMST trên thế giới thường áp dụng hài hòa giữa giáo dục khai phóng và giáo dục tư duy thiết kế [1]. Ở một số khía cạnh, đào tạo theo phương thức CDIO (Conceive, Design, Implementing, Operation - Hình thành ý tưởng, Thiết kế, Thực hiện và Vận hành) cũng khá tương thích và hiệu quả đối với giáo dục ĐMST,... Giáo dục phát triển năng lực học tập suốt đời cần được tập trung để hỗ trợ nâng cao kỹ năng xử lý thông tin, cập nhật kiến thức, kỹ năng mới và tinh thần sẵn sàng thử nghiệm các ý tưởng cho người học. Các hoạt động dạy và học như vậy sẽ hỗ trợ sự hình thành tư duy sáng tạo, tư duy thiết kế của sinh viên, góp phần tạo nên một thế hệ nhân lực mới không những có tư duy 
mà cả khả năng thực thi hoạt động $R \& D$ và ĐMST.

Đại học thông minh được xây dựng dựa trên việc kích thích và hỗ trợ sự phát triển của tư duy, ý tưởng khởi nghiệp và kỹ năng số. Trong bối cảnh này, trước hết, đào tạo về tinh thần khởi nghiệp và kỹ năng số cho giảng viên được thực hiện ở tất cả các bộ phận của trường đại học. Sau đó, đội ngũ giảng viên thực hiện phương pháp tiếp cận khởi nghiệp và kỹ năng số để giảng dạy ở tất cả các khoa, thúc đẩy sự đa dạng và tư duy ĐMST trong giảng dạy và học tập. Không thay đổi từ giảng viên, công cuộc đổi mới sẽ không hiện thực hóa được.

Đối với sự thay đổi thị trường lao động và xu hướng việc làm, sự thay đổi về bối cảnh công nghệ và môi trường của các lĩnh vực được đề cập trong mục 2.2 , các trường đại học sẽ cung cấp các khóa học, học phần rất linh hoạt $[4,8,9]$. Ví dụ như thực hiện mô hình thay đồi biên (đại hoc jukebox): đây là mô hình đào tạo đa khuôn viên có độ linh hoạt cao, bắt đầu có tính liên thông và đặc trưng đào tạo cá thể hóa; cho phép sinh viên tích lũy tín chỉ trực tiếp và trực tuyên tại các trường đại học trong mạng lưới đối tác. Ví dụ khác nữa là mô hình thích ứng (đai học uber hóa) để cung cấp các chương trình cấp bằng phi truyền thống và tăng cường sử dụng các chế độ học tập linh hoạt cho sinh viên, thúc đẩy quá trình học tập suốt đời. Tương tự như dịch vụ giao thông đô thị Uber, cả giảng viên cơ hữu và giảng viên tự do tham gia giảng dạy. Theo đó giáo dục được thúc đẩy bởi nhu cầu, tự điều chỉnh, không rắc rối, rất dễ tiếp cận và thuận tiện. Mô hình chứng chỉ nano/micro là mô hình thay đổi triệt để nhất. Mô hình này tổ chức đào tạo cấp các chứng nhận thành phần (nano/micro) thông qua các chương trình đào tạo các tín chỉ phi truyền thống do các tổ chức/cá nhân thực hiện và được cả đại học và doanh nghiệp thừa nhận. Mô hình đào tạo định hướng doanh nghiệp này đang thu hút sự quan tâm của thế hệ công dân bản địa kỹ thuật số.

\section{Nghiên cưu định hướng ĐMST}

Mặc dù việc khai thác bí quyết trở thành sứ mệnh thứ ba của trường đại học, việc nghiên cứu để tạo ra tri thức tiên tiến chuyên sâu vẫn rất quan trọng. Vì mục đích này, không chỉ các ấn phẩm khoa học có chỉ số trích dẫn cao mà kêt quả nghiên cứu còn được đo lường các bằng sáng chế đã được chấp nhận đơn (tại tất cả các vùng và các khu vực pháp lý), các bằng sáng chế đã cấp (tất cả các khu vực pháp lý), số lượng bản quyền sở hữu trí tuệ đã được chuyển giao và kinh phí thu nhận được. Đặc biệt, các nghiên cứu mang tính liên ngành và xuyên ngành, trong đó các nhà khoa học, công nghệ kỹ thuật và nhà thiết kế của nhiều ngành cùng tham gia nghiên cứu sẽ được phát triển phổ biến, thay thế cho các nghiên cứu chuyên sâu, đơn ngành của từng cá nhân, từng nhóm. Cách thức tổ chức nghiên cứu như vậy mới thực sự triển khai được ĐMST và mang lại lợi ích kinh tế - xã hội cho cộng đồng.

Ngoài ra, các nghiên cứu của trường đại học có chức năng trực tiếp phát triển hoạt động khởi nghiệp và ĐMST. Tinh thần khởi nghiệp không còn được coi là một phương tiện làm giàu cho bản thân, mà nói chung, hoạt động nghiên cứu của trường đại học có mục đích phát triển khoa học, công nghệ, khoa học xã hội và nhân văn và đặc biệt phát triển năng lực ĐMST để ứng phó với các thách thức và cơ hội nhằm nâng cao giá trị gia tăng của nền kinh tể, hiện thực hóa mục tiêu quốc gia giàu có và thịnh vượng. Theo tiếp cận đó, nhiều sinh viên đã quan tâm đến việc tạo dựng cuộc sống của chính mình, thay vì chỉ trở thành một bánh răng trong guồng quay của doanh nghiệp. Kết quả là, ngoài việc tìm kiếm việc làm, sinh viên còn tích cực tạo ra các công ty mới dựa trên công nghệ và giải pháp của riêng họ. Một số công ty trong số đó có thể sẽ thành công. $\mathrm{Xu}$ hướng này đang phát triển mạnh ở các nước Châu Á.

Chuẩn mưc xã hội và hệ sinh thái

Trường đại học đã phát triển để trở thành một tổ chức hoàn thiện đến mức mà nó được kết nối với nhiều thành tố khác của thế giới để tạo nên các hệ sinh thái. Theo Ronald Barnett [3], có bảy hệ sinh thái đặc biệt quan trọng đối với trường đại học. Đó là hệ sinh thái tri thức, thể chế xã hội, con người, kinh tế, dạy-học, văn hóa và môi trường tự nhiên. Tuy nhiên, trong 50 vừa năm qua, trường đại học chưa quan tâm đầy đủ đến các khía cạnh này. Trong thế kỷ 21 , các hệ sinh thái này không đứng ngoài trường 
đại học, mà ngược lại, chúng và trường đại học hòa nhập và tương tác với nhau rất mạnh mẽ. Thông qua mối liên kết này, từng hệ sinh thái đó đã trở thành một "hệ sinh thái đặc thù" của trường đại học với vị trí và mối quan hệ đặc thù. Các trường đại học có trách nhiệm tìm ra các khả năng riêng của mình trong việc thúc đẩy phúc lợi của bảy hệ sinh thái đó. Theo cách tiếp cận thực tế và khả thi, đó là trách nhiệm thực hiện 17 mục tiêu phát triển bền vững (SDGs) của Liên Hợp Quốc, bao gồm: xoá nghèo, không còn nạn đói, sức khỏe và cuộc sống tốt, giáo dục có chất lượng, bình đẳng giới, nước sạch và vệ sinh môi trường; năng lượng sạch và giá cả hợp lý, công việc tốt và tăng trưởng kinh tế; công nghiệp, ĐMST và cơ sở hạ tầng; giảm bất bình đẳng; thành phố và cộng đồng bền vững; tiêu dùng và sản xuất có trách nhiệm; hành động về biến đổi khí hậu; tài nguyên và môi trường biển; tài nguyên và môi trường trên đất liền; hòa bình và công lý thể chế mạnh mẽ; quan hệ đối tác vì các mục tiêu. Cụ thể, các nghiên cứu khoa học cần có tác động đến các mục tiêu trên. Đồng thời, các trường đại học cần nỗ lực triển khai đào tạo cá thể hoá để đáp ứng các yêu cầu học tập suốt đời và các hoạt động gắn kết cộng đồng. Tác động của trường đại học đối với sự phát triển bền vững của cộng đồng được thúc đầy và các chuẩn mực xã hội (như các hoạt động hoàn lương, hỗ trợ sinh viên gặp khó khăn, giúp đỡ người nghèo và người bị ảnh hưởng bởi thiên tai) được xây dựng một cách hài hòa. Cuối cùng nhưng không kém phần quan trọng là vấn đề đạo đức thông tin, bao gồm tính toàn vẹn trong học tập, các hành vi đạo đức, các biện pháp bảo mật điện tử được đảm bảo. Tóm lại, trường đại học không chỉ là một hệ sinh thái mà còn là một trường đại học đạo đức.

\subsection{Thành tố đổi mói sáng tạo đặc thù}

Các loại hình ĐMST cơ bản, bao gồm ĐMST tiên phong (pioneering innovation), ĐMST thực hành hiệu quả (best practice innovation) và ĐMST về công nghệ (technological innovation). Chi tiết ra, còn có các loại hình khác như ĐMST triển khai bí quyết nhanh (first mover), ĐMST mỏ (open innovation), ĐMST tiếp cận công nghệ nhanh (fast followers), ĐMST tối ưu hoá, ĐMST về giải pháp,... Mỗi nhóm trường đại học với sứ mệnh và phân khúc thị trường của mình có thể áp dụng phương thức phù hợp để đáp ứng sứ mệnh. Trong đó, ĐMST tiên phong là phương thức ĐMST tiêu biểu nhất. ĐMST tiên phong liên quan đến những sản phẩm, mô hình hoặc dịch vụ hoàn toàn mới, có đặc trưng thương hiệu được đưa vào thị trường. Loại ĐMST này không nhiều, nên sản phẩm, dịch vụ hoặc cách làm mới sẽ hoàn toàn là nguyên bản và lần đầu tiên xuất hiện. ĐMST tiên phong liên quan đến các phát minh. Đó sẽ là lợi thế của các trường đại học định hướng nghiên cứu (hoặc các trường đại học nghiên cứu xuất sắc) nhóm $2,3,4$ và 5 . Các trường đại học thực hiện thành công loại hình ĐMST này sẽ trở thành người tiên phong (first mover) tạo ra những thay đổi đột phá.

ĐMST thực hành hiệu quả được phát triển rộng rãi hơn. Đối với loại hình ĐMST này, các doanh nghiệp hoặc tổ chức thực hiện ĐMST bằng cách thực hiện tái cấu trúc nội bộ sử dụng kết quả đối sánh (benchmarking) hoặc áp dụng giải pháp của các doanh nghiệp khác.

ĐMST về công nghệ tập trung vào các khía cạnh công nghệ của sản phẩm, dịch vụ hoặc quy trình mới hoặc được cải tiến. Việc thực hiện loại hình ĐMST này có thể được thực hiện với các bằng sáng chế công nghệ có bản quyền của các trường, nhưng cũng có thể áp dụng các công nghệ mở, tức là thông qua ĐMST mở. Việc áp dụng hai kiểu ĐMST này không quá phức tạp, có thể triển khai được ngay cả đối với các trường đại học định hướng ứng dụng. Hiện nay, ĐMST về công nghệ diễn ra nhanh hơn và ở quy mô nhỏ hơn nhiều so với trước đây, đòi hỏi phải tạo ra nhu cầu và không gian khuyến khích, thúc đẩy việc hình thành và chuyển giao nhanh chóng các ý tưởng.

Lưu ý rằng, cụm từ "ĐMST về công nghệ" (technological innovation) cũng được sử dụng như "ĐMST công nghệ" (technology innovation). Trong bối cảnh này, "ĐMST công nghệ" nhấn mạnh yếu tố sáng tạo công nghệ và vì lợi ích của công nghệ đó. Khi đó, "ĐMST về công nghệ" chỉ tập trung vào việc trường đại 
học định hướng ứng dụng thực hiện cải tiến giá trị doanh nghiệp dựa vào trên các khía cạnh công nghệ của sản phẩm hoặc dịch vụ, còn ĐMST công nghệ liên quan đển sáng tạo công nghệ chỉ là ưu tiên của các trường đại học định hướng nghiên cứu.

\section{4. Đánh giá mức độ thích ứng đối với mô hình đại học định hướng đổi mới sáng tạo}

\subsection{Phuoong pháp đánh giá và đối sánh}

Hệ thống đánh giá chất lượng giáo dục đại học của UPM bao gồm 52 tiêu chí trong 8 tiêu chuẩn, bao gồm Định hướng chiến lược, Đào tạo, Nghiên cứu, ĐMST, Hệ sinh thái đại học, Chuyển đổi số, Quốc tế hóa và Phục vụ cộng đồng, phản ánh bao quát tất cả các lĩnh vực hoạt động của trường đai học, tức là bao gồm cả hai tầng chính (tầng nền tảng về đào tạo và nghiên cứu truyền thống và tầng $Đ M S T$ phổ quát và ĐMST đặc thù). Đối với khả năng thích ứng của các trường đại học trong kỷ nguyên $\mathrm{CMCN} 4.0$, việc đánh giá chỉ tập trung vào ba yêu cầu: đổi mới căn bản tư duy, ĐMST toàn diện, khuyến khích các hệ sinh thái và thúc đẩy chuẩn mực xã hội, tức là chỉ đối với những nội dung ĐMST phổ quát và ĐMST đặc thù. Với mục đích này, 30/52 chỉ số của hệ thống xếp hạng đối sánh của UPM đã được lựa chọn và phân theo 4 nhóm tiêu chuẩn: Đào tạo, Nghiên cứu và ĐMST, Chuyển đổi số và Hệ sinh thái và các chuẩn mực xã hội như trình bày trong Bảng 1 , trong đó nhóm tiêu chuẩn về Đào tạo bao gồm cả các nội dung về thay đổi tư duy toàn diện, lãnh đạo và quản trị, con người và giáo dục ĐMST. Tiêu chí của Hệ sinh thái và các chuẩn mực xã hội bao gồm các yếu tố của hệ sinh thái đại học, phục vụ cộng đồng và các chuẩn mực xã hội.

Các chỉ báo của hệ thống UPM phản ánh hiện trạng, mức độ cải tiến và kết quả đạt được của tiêu chí và nội dung được đánh giá. Đó là cơ sở để đối sánh chất lượng. Các tiêu chí đều yêu cầu mô tả cụ thể kèm theo minh chứng hoặc số liệu liên quan đến các nội dung cụ thể của các hoạt động; được đo lường định tính hoặc định lượng. Giá trị chuẩn của các ác tiêu chí định lượng được đánh giá bằng con số thống kê theo giá trị kết quả trung bình của các trường đại học xuất sắc trong top 1000 thế giới. Các tiêu chí định tính được đánh giá theo thang điểm từ mức 1 đến mức 6 hoặc 7 theo tiếp cận của mô hình đảm bảo chất lượng của Mạng lưới các trường đại học Đông Nam Á (AUN-QA). Trong trường hợp này, các tiêu chí có thể đạt được mức 4 khi các hoạt động thực hành đầy đủ như mong đợi. Mức đánh giá cho tiêu chí sẽ cao hơn nếu kết quả đạt được tốt hơn mức phù hợp hoặc đã trở thành điển hình quốc gia và quốc tế. Mốc chuẩn đối sánh của các tiêu chuẩn và tiêu chí cũng được trình bày trong Bảng 1 .

\subsection{Số liệu phân tích}

Mô hình đại học định hướng ĐMST phổ quát có thể tiếp cận từ cả hai nhóm đại học nghiên cứu và đại học ứng dụng. Tuy nhiên, gợi mở này còn mới đối với nhóm đại học ứng dụng. Theo truyền thống, hoạt động ĐMST thường gắn liền với hoạt động nghiên cứu và triển khai $(\mathrm{R} \& \mathrm{D})$, do đó thường được coi là thuộc tính của các CSGDĐH định hướng nghiên cứu và kết quả ĐMST cũng chỉ có ở nhóm đại học này. Trong nghiên cứu này, dữ liệu xếp hạng đối sánh được thu thập trong năm 2021 từ 10 trường đại học định hướng nghiên cứu của Việt Nam: Trường Đại học Bách khoa Hà Nội, Trường Đại học Khoa học Tự nhiên (ĐHQGHN), Trường Đại học Công nghệ (ĐHQGHN), Trường Đai học Thủy lợi, Trường Đại học Giao thông vận tải, Trường Đại học Xây dựng Hà Nội, Trường Đại học Mỏ - Địa chất, Trường Đại học Dược Hà Nội, Trường Đại học Phenikaa và Trường Đại học Khoa học (ĐH Huế).

Để đối sánh, dữ liệu UPM của 5 trường đại học của Thái Lan cũng được sử dụng, bao gồm: Trường Đại học Mae Fah Luang, Trường Đại học Srinakharinwirot, Trường Đại học Burapha, Trường Đại học Kasetsart và Trường Đại học Maejo. Mặc dù ba CSGDĐH đầu tiên trong nhóm này là các đại học đa lĩnh vực, còn hai CSGDĐH còn lại tập trung vào lĩnh vực khoa học nông nghiệp, nhưng tất cả đều là các trường đại học định hướng nghiên cứu thuộc nhóm 4 và 5 sao theo tiêu chí UPM.

Số liệu và minh chứng do các trường trực tiếp cung cấp cho hệ thống UPM, được các chuyên gia của hệ thống UPM thẩm định và sử 
dụng để xếp hạng, gắn sao cho các trường. Theo quy định, đây là các số liệu có bản quyền thuộc về các trường và hệ thống UPM. Để phân tích, UPM chỉ cung cấp số liệu phân tích chung, trung bình của các nhóm trường (Việt Nam và Thái Lan), không đi chi tiết riêng cho từng trường. Dữ liệu thu được được liệt kê trong Bảng 1 cho giá trị trung bình đối với kết quả thực tế của các trường cùng với của các giá trị chuẩn dùng để đối sánh của hệ thống UPM. Kết quả này cũng được trình bày trong các Hình 3-6.

Bảng 1. Các tiêu chuẩn, tiêu chí đánh giá mức độ ĐMST trích từ hệ thống xếp hạng đối sánh UPM và dữ liệu xếp hạng đối sánh trung bình của các trường đại học Việt Nam và Thái Lan từ nguồn UPM [7]

\begin{tabular}{|c|c|c|c|c|}
\hline \multirow{2}{*}{ STT } & \multirow{2}{*}{ Tiêu chuẩn và tiêu chí } & \multirow{2}{*}{$\begin{array}{l}\text { Giá trị } \\
\text { chuần }\end{array}$} & \multicolumn{2}{|c|}{ Giá trị trung bình } \\
\hline & & & Việt Nam & Thái Lan \\
\hline 1 & \multicolumn{4}{|l|}{ Đào tạo } \\
\hline 1.1 & Chiến lược thích ứng với cách mạng công nghiệp lần thứ tư & 6 & 5,2 & 6,0 \\
\hline 1.2 & Chính sách kiến tạo cho người học & 6 & 4,7 & 5,4 \\
\hline 1.3 & Chất lượng tuyển sinh & 25 & 19,2 & 24,2 \\
\hline 1.4 & Trình độ giảng viên & 70 & 51,5 & 62,3 \\
\hline 1.5 & $\begin{array}{l}\text { Cấu trúc và nội dung CTĐT đáp ứng yêu cầu cuộc cách mạng } \\
\text { lần thứ tư }\end{array}$ & 5 & 3,1 & 3,2 \\
\hline 1.6 & Đào tạo cá thể hóa & 7 & 4,1 & 4,8 \\
\hline 1.7 & Nghiên cứu khoa học và khởi nghiệp của sinh viên & 7 & 5,1 & 5,2 \\
\hline 2 & \multicolumn{4}{|l|}{ Nghiên cứu và ĐMST } \\
\hline 2.1 & Công bố quốc tế & 1.5 & 1,6 & 1,4 \\
\hline 2.2 & Chất lượng nghiên cứu & 10 & 8,2 & 6,3 \\
\hline 2.3 & Chỉ số xếp hạng nghiên cứu của Scimago & 4 & 1,1 & 2,6 \\
\hline 2.4 & Sở hữu trí tuệ trong nước & 25 & 8,5 & 76,0 \\
\hline 2.5 & Sở hữu trí tuệ quốc tế & 6 & 0,9 & 0,6 \\
\hline 2.6 & Kinh phí nghiên cứu và đổi mới sáng tạo & 15 & 16,8 & 14,3 \\
\hline 2.7 & Doanh nghiệp khởi nghiệp, spin-off & 5 & 3,8 & 10,6 \\
\hline 2.8 & Chỉ số xếp hạng đổi mới sáng tạo của Scimago & 4 & 1,1 & 2,6 \\
\hline 3 & \multicolumn{4}{|l|}{ Chuyển đổi số } \\
\hline 3.1 & Quản trị và phân tích thông tin & 7 & 4,3 & 5,0 \\
\hline 3.2 & Tài nguyên số & 20 & 9,7 & 64,6 \\
\hline 3.3 & Mức độ sử dụng tài nguyên số & 5 & 4,1 & 1,4 \\
\hline 3.4 & Mức độ tương tác học thuật trực tuyến & 2 & 2,3 & 0,7 \\
\hline 3.5 & Bài giảng điện tử & 5 & 2,8 & 3,6 \\
\hline
\end{tabular}




\begin{tabular}{|l|l|l|l|l|}
\hline 3.6 & Dạy-học kết hợp & 50 & 33,8 & 38,0 \\
\hline 3.7 & Ú́ng dụng hệ thống thực - ảo (CPS) & 3 & 1,5 & 2,6 \\
\hline 3.8 & Đạo đức thông tin & 1 & 0,5 & 1,6 \\
\hline 4 & Hệ sinh thái và các chuẩn mực xã hội & \multicolumn{4}{l|}{} \\
\hline 4.1 & Môi truờng dạy-học, nghiên cứu triển khai (R\&D) và ứng dụng & 7 & 5,1 & 5,4 \\
\hline 4.2 & Không gian sáng tạo và hỗ trợ khởi nghiệp & 7 & 3,9 & 5,0 \\
\hline 4.3 & Khuôn viên đại học & 7 & 3,8 & 4,8 \\
\hline 4.4 & Đối tác doanh nghiệp & 2 & 2,3 & 4,1 \\
\hline 4.5 & Phát triển năng lực học tập suốt đời & 1 & 0,6 & 0,8 \\
\hline 4.6 & Chỉ số ảnh hưởng của các nghiên cứu về phát triển bền vững & 15 & 19,1 & 31,4 \\
\hline 4.7 & Thúc đẩy các chuẩn mực xã hội & 5 & 8,2 & 17,0 \\
\hline
\end{tabular}

\subsection{Kết quả và nhận xét}

\subsubsection{Về đào tạo}

Kết quả đối sánh của 7 tiêu chí trong nhóm tiêu chuẩn về đào tạo được trình bày trên Bảng 1 . Giá trị chuẩn hoá của chúng được minh hoạ trên 3. Nhận thấy rằng, các trường đại học định hướng nghiên cứu của Việt Nam khảo sát trong nghiên cứu này đã tiếp cận mốc chuẩn tốt nhất đối với các tiêu chí về: i) Sự thích ứng của chiến lược phát triển với $\mathrm{CMCN} 4.0$; ii) Thực hiện chiển lược; iii) Chất lượng giảng viên; và iv) Nghiên cứu khoa học của sinh viên. Trong đó, sự tương thích về chiến lược đạt mức cao nhất (87\%).

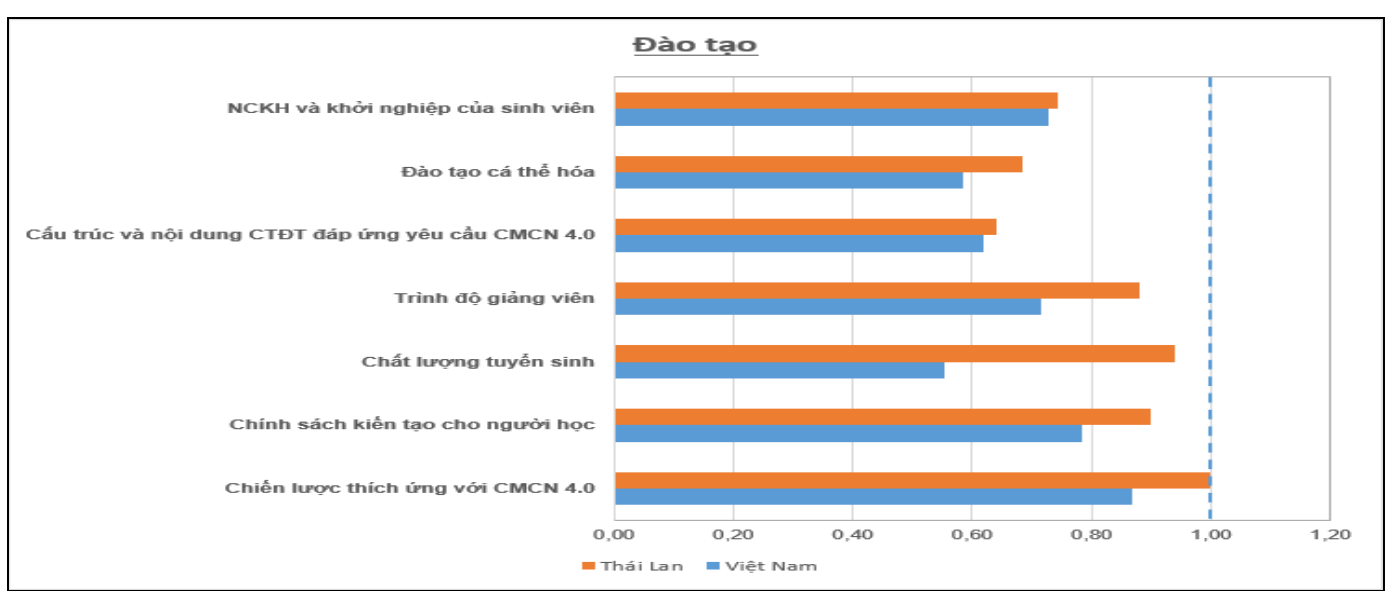

Hình 3. Kết quả đánh giá đã được chuẩn hoá cho các tiêu chí trong nhóm tiêu chuẩn về Đào tạo.

Chiến lược và mục tiêu phát triển của đa số các trường đại học của Việt Nam đã có đề cập đến $\mathrm{CMCN} 4.0$, nghiên cứu, chuyển giao tri thức và học tập suốt đời. Tuy nhiên các mục tiêu và giải pháp trực tiếp cho khởi nghiệp và đổi mới sáng tạo còn chưa rõ ràng mặc dù nội dung về khởi nghiệp đã được đề cập trong
Khung trình độ quốc gia. Chuyển đổi số được trao đổi nhiều trong các hội nghị, hội thảo nhưng công bố chính thức thành hành động của các trường chưa được thể hiện nhiều. Trong lúc đó, đối với các trường đại học của Thái Lan mục tiêu khởi nghiệp và đổi mới sáng tạo hầu như đã sẵn sàng từ hơn 10 năm trước. So với 
mốc chuẩn yêu cầu $70 \%$ giảng viên có trình độ tiến sĩ của UPM, các trường đại học Việt Nam đã đạt trung bình $51,5 \%$ (đối với các trường đại học của Thái Lan là 63,3\%). Được biết, đây là một tỷ lệ cao, đang dẫn đầu trong cả nước (vì nếu tính trung bình cho cả nước, Việt Nam mới chỉ đạt tỷ lệ trung bình khoảng $30 \%$ ).

Nghiên cứu khoa học và khởi nghiệp của sinh viên đã được tổ chức có nền nếp, hầu hết sinh viên của các trường của Việt Nam đều đã đạt các giải thưởng cấp Bộ, tuy nhiên giải thưởng quốc tế chưa nhiều. Về tiêu chí này, Việt Nam và Thái Lan có sự tương đồng.

Về các điểm cần cải tiến, các trường đại học Việt Nam đặc biệt cần quan tâm đến chất lượng tuyển sinh. Trong lúc chất lượng tuyển sinh của các trường đại học Thái Lan khá tốt (điểm tuyển sinh trung bình đạt 24,2/30 điểm), thì nhóm đại học này của Việt Nam chỉ đạt 19,2/30 điểm. Nếu tách riêng một số trường đại học có chất lượng tuyển sinh tốt như Trường Đại học Bách khoa Hà Nội, Trường Đại học Công nghệ - Đại học Quốc gia Hà Nội và Trường Đại học Dược Hà Nội thì điểm trung bình của các trường còn lại còn thấp hơn nữa. Đây là một bất cập lớn cho các trường đại học nghiên cứu của Việt Nam trong việc thực hiện chiến lược ĐMST tiên phong, dựa vào các phát minh, sáng chế và phát triển đội ngũ các nhà công nghệ kỹ thuật trẻ tài năng phục vụ công nghiệp hoá, hiện đại hoá đất nước.

Đối với việc cập nhật nội dung chương trình đào tạo và triển khai đào tạo cá thể hoá, kết quả thực hiên của Việt Nam và Thái Lan cũng chưa triển khai được nhiều. Một số trường đã xây dựng và triển khai một vài chương trình đào tạo mới liên quan đến các công nghệ 4.0 như Trí tuệ nhân tạo, Dữ liệu lớn, Kinh tế số,... Một số kiến thức và công nghệ 4.0 được cập nhật ở một mức độ nào đó trong các môn học đã và đang giảng dạy, nhưng sự thay đổi cắn bản và toàn diện chưa được thể hiện rõ ràng. Kiến thức tin học vẫn đang được giảng dạy theo các giáo trình truyền thống, nội dung giảng dạy về tư duy và kỹ năng khởi nghiệp và kỹ năng số chưa được thiết kế và triển khai đầy đủ, đồng bộ thành khối kiến thức chung của tất cả các ngành học. Đối với việc đào tạo cá thể hoá, mặc dù có kết quả nhỉnh hơn, nhưng nói chung mục tiêu này mới được hiện thực hoá bằng danh mục các môn học tự chọn trong các chương trình đào tạo và việc triển khai sự lựa chọn ấy vẫn còn khá khiêm tốn. Việc trao đổi tín chỉ giữa các chương trình đào tạo ở các khoa khác nhau trong nội bộ trường hầu như chưa có, số sinh viên tốt nghiệp trước thời hạn vô cùng nhỏ.

4.3.2. Nghiên cứu và đối mới sáng tạo

Hình 4 trình bày kết quả phân tích của các tiêu chí trong nhóm tiêu chuẩn Nghiên cứu và ĐMST. Về tổng thể có thể thấy rất rõ rằng, trong khi có sự tương đồng khá tốt giữa các trường đại học của hai nước đối với hầu hết các tiêu chí nghiên cứu, chỉ số về số lượng bằng sáng chế và giải pháp hữu ích đăng ký trong nước và chỉ số về số lượng các doanh nghiệp khởi nghiệp của Thái Lan vượt trội so với cả mốc chuẩn và kết quả của Việt Nam. Tương tự, các chỉ số chất lượng nghiên cứu và ĐMST do bảng xếp hạng Scimago phân tích cũng cho thấy sự vượt trội của Thái Lan so với Việt Nam. Đây như là một hệ quả khác biệt tất yếu do tác động của việc xác lập rõ ràng chiến lược và văn hoá ĐMST của các trường đại học Thái Lan như đã phân tích ở trên. Việc triển khai chiến lược đó đã nâng cao năng lực chuyển hóa các kết quả từ các công trình nghiên cứu khoa học sang sản phẩm ứng dụng và phát triển thành công ty spin-off.

Về chi tiết, kết quả cho thấy Việt Nam vẫn có một số lợi thế về số lượng và chỉ số trích dẫn của các công bố quốc tế và tỷ lệ kinh phí đầu tư cho nghiên cứu và ĐMST. Các chỉ số này của các trường đại học Việt Nam đều đã vượt qua các trường đại học Thái Lan. Điều này giải thích tại sao Việt Nam có các trường đại học được xếp hạng trong top 1000 trường đại học hàng đầu thế giới của bảng xếp hạng $\mathrm{QS}$ và THE (Hình 4).

\subsubsection{Chuyển đổi số}

Hình 5 trình bày kết quả đánh giá cho các tiêu chí thuộc nhóm tiêu chuẩn Chuyển đổi số. Đây là các tiêu chí mới, trong giai đoạn khởi động, các giá trị của mốc chuẩn đối sánh đặt ra không quá cao. Đặc biệt, ở giai đoạn này UPM mới chỉ tâp trung vào các nội dung cốt lõi và cơ bản nhất của chuyển đổi số như: khả năng quản 
trị và phân tích thông tin; độ phong phú của học liệu số; mức độ truy cập tài nguyên số; mức độ tương tác trong dạy - học và đạo đức thông tin. Tuy nhiên, hầu hết các giá trị trung bình của các tiêu chí được đánh giá đều ở dưới mức yêu cầu. Có vẻ như, trước đại dịch COVID-19, phần lớn các trường đại học vẫn đang thực hiện các chiến lược chuyển đổi số đơn giản, chỉ tự giới hạn số hóa các quy trình và dịch vụ quản trị dựa trên tài liệu bản in, chưa có quy trình hoàn thiện cho việc chuyển đổi số và kế hoạch chuyển đổi số không được xác định. Do đó, một số hoạt động như: mức độ truy cập học liệu và tương tác trong quá trình dạy - học đã được thực hiện trong thực tế, nhưng các công cụ quản lý không được xây dựng. Do đó, các trường không thể cung cấp dữ liệu của các thông số này để phục vụ mục đích đánh giá. Các khóa học trực tuyến (bài giảng được ghi lại, bài giảng trực tiếp,...) của các chương trình đào tạo chưa được thực hiện thông qua các kết nối trên cổng thông tin của trường, việc hỗ trợ các mô hình học tập kết hợp hoặc/và cá thể hóa vẫn còn đang thuê mượn, thụ động. Các bài giảng điện tử, học liệu số đang còn phổ biến ở những cấp độ thấp, đơn giản, tức là chủ yếu sử dụng các trình chiếu và trao đổi hệ thống thư điện tử. Các bài điện tử với việc giảng dạy được ghi lại và giảng dạy trực tiếp còn rất hiếm. Mức độ ứng dụng hệ thống thực-ảo (CPS) vào dạy-học và quản lý còn khiêm tốn. Hơn nữa, đạo đức thông tin, bao gồm tính minh bạch trong học thuật, các hành vi đạo đức, các biện pháp bảo mật điện tử chưa được đảm bảo hoàn toàn.

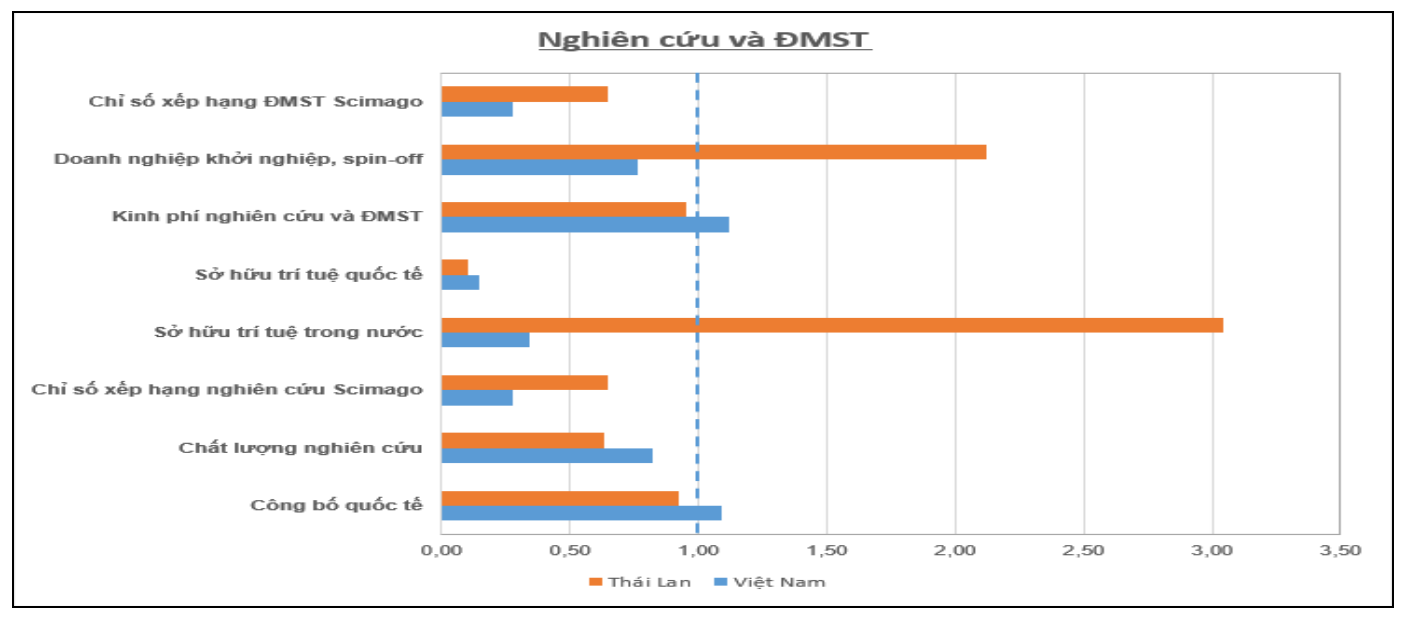

Hình 4. Kết quả đánh giá đã được chuẩn hoá cho các tiêu chí trong nhóm tiêu chuẩn về Nghiên cứu và ĐMST.

Phân tích chi tiết cho thấy rằng các chỉ số trong nhóm Chuyển đổi số của các trường đại học Thái Lan đều nhỉnh hơn so với các trường đại học Việt Nam, ngoại trừ 2 chỉ số mức độ truy cập tài nguyên học thuật và mức độ tương tác học tập. Đầu tiên, các chỉ số cao hơn như tài nguyên số, hệ thống thực-ảo (CPS), đạo đức thông tin phản ánh sự đầu tư và quyết tâm chuyển đổi số của các trường đại học Thái Lan. Họ có cơ sở vật chất sẵn sàng phục vụ nhu cầu học tập và giảng dạy trực tuyến, cũng như hỗ trợ sinh viên trong việc truy cập học liệu, mức độ bảo mật thông tin và sử dụng các phần mềm kiểm tra sự trùng lặp, chống đạo văn thậm chí vượt mức yêu cầu của chỉ số này. Tuy nhiên, các chỉ số về mức độ truy cập tài nguyên học tập và mức độ tương tác trực tuyến cho thấy phương pháp dạy và học chưa được đổi mới triệt để. Các sinh viên chưa phát huy lợi thế của việc sử dụng học liệu trực tuyến cũng như tương tác với giảng viên và nhóm môn học (Hình 5).

4.3.4. Hệ sinh thái và các chuẩn mực xã hội

Kết quả đánh giá đối với các tiêu chí thuộc nhóm tiêu chuẩn Hệ sinh thái đại học và các chuẩn mực xã hội được trình bày trong Hình 6 . Nói chung, đối với chỉ số này, các trường đại học Việt Nam đều thuộc tốp đầu trong tương quan toàn quốc. Tuy nhiên, xét theo tiêu chuẩn của 1000 trường đại học hàng đầu thế giới về 
cơ sở vật chất phục vụ đào tạo, nghiên cứu, hỗ trợ khởi nghiệp cũng như mức độ đáp ứng của khuôn viên trường, các chỉ số nêu trên vẫn đang ở mức thấp. Đối với hệ sinh thái đại học, số lượng các doanh nghiệp và tổ chức có quan hệ hợp tác trong đào tạo, nghiên cứu và phát triển các dự án khởi nghiệp của sinh viên; tài trợ cho nghiên cứu hoặc/và có sự hợp tác trong hoạt động $R \& D$ với kết quả là các công trình khoa học công bố chung hoặc cùng đăng ký sáng chế đã được thiết lập và chia sẻ. Chỉ số này được đánh giá không chỉ qua các văn bản hợp tác và hợp đồng ký kết mà còn bởi sự hiện diện của các doanh nghiệp trong các hoạt động và sự kiện của trường. Do đó, hệ sinh thái đại học đã có đầy đủ quan hệ và tác động của các bên liên quan, từ cán bộ, giảng viên, sinh viên đến doanh nghiệp và các nhà sử dụng lao động nói chung. Trong hệ sinh thái đó, các trường đại học này không chỉ là bên nhận mà đồng thời có đóng góp tích cực và hiệu quả, thúc đẩy tác động của trường đại học đối với sự phát triển bền vững của cộng đồng (chẳng hạn như biến đổi khí hậu, chương trình tiết kiệm năng lượng, chương trình bảo tồn nước, chương trình tái chế, chính sách giao thông,...) và trong việc xây dựng các chuẩn mực xã hội hài hòa (chẳng hạn như các hoạt động đền ơn đáp nghĩa, hỗ trợ học sinh gặp khó khăn, giúp đỡ người nghèo, đồng bào bị ảnh hưởng bởi thiên tai). Các hoạt động này được các hội sinh viên tham gia rộng rãi và khởi xướng. Trên thực tế, đa phần các hoạt động gắn kết cộng đồng vừa nêu của các trường đại học Việt Nam đều do Đoàn thanh niên và Hội sinh viên khởi xướng và tổ chức thực hiện, do đó tính học thuật chưa cao.

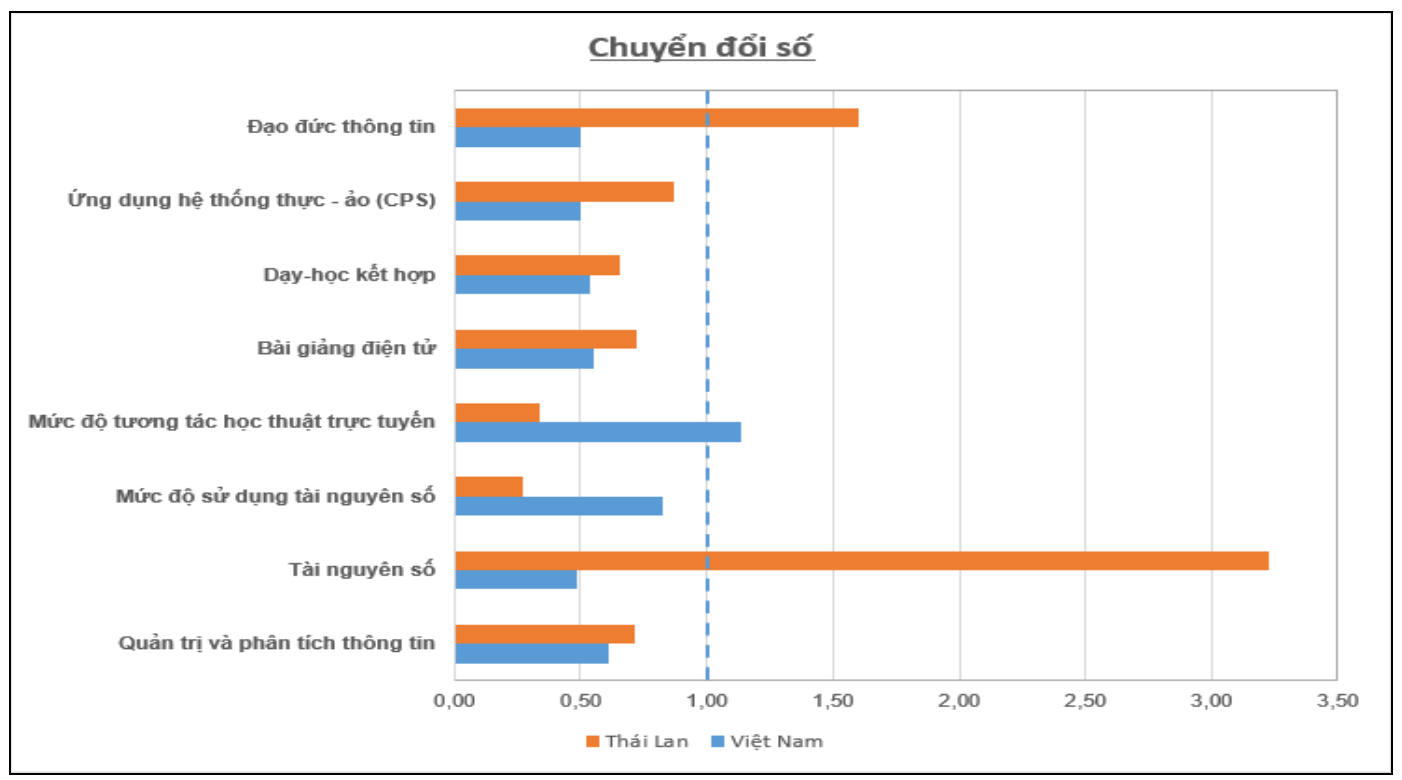

Hình 5. Kết quả đánh giá đã được chuẩn hoá cho các tiêu chí trong nhóm tiêu chuẩn về Chuyển đổi số.

Đối với các trường đại học Thái Lan, các hoạt động gắn kết cộng đồng như hỗ trợ nhu cầu học tập suốt đời, truyền thông tầm quan trọng và triển khai các nghiên cứu phục vụ 17 mục tiêu phát triển bền vững của Liên Hợp quốc được thực hiện rất hiệu quả, có kết quả vượt trội so với Việt nam. Trong đó, các tiêu chuẩn về thúc đẩy các chuẩn mực xã hội và đặc biệt, chỉ số tác động của các nghiên cứu liên quan đến 17 mục tiêu phát triển bền vững và số lượng đối tác doanh nghiệp đã vượt quá mốc chuẩn đối sánh rất nhiều. Nhờ vào các nghiên cứu liên quan tới 17 mục tiêu phát triển bền vững, cùng khả năng triển khai ứng dụng và phát triển khởi nghiệp, các trường đại học Thái Lan có thể hỗ trợ người dân ở địa phương bằng những sản phẩm của mình, đồng thời tạo cơ hội trải nghiệm cho các sinh viên đang học và đáp ứng nhu cầu học tập suốt đời của cựu người học. 


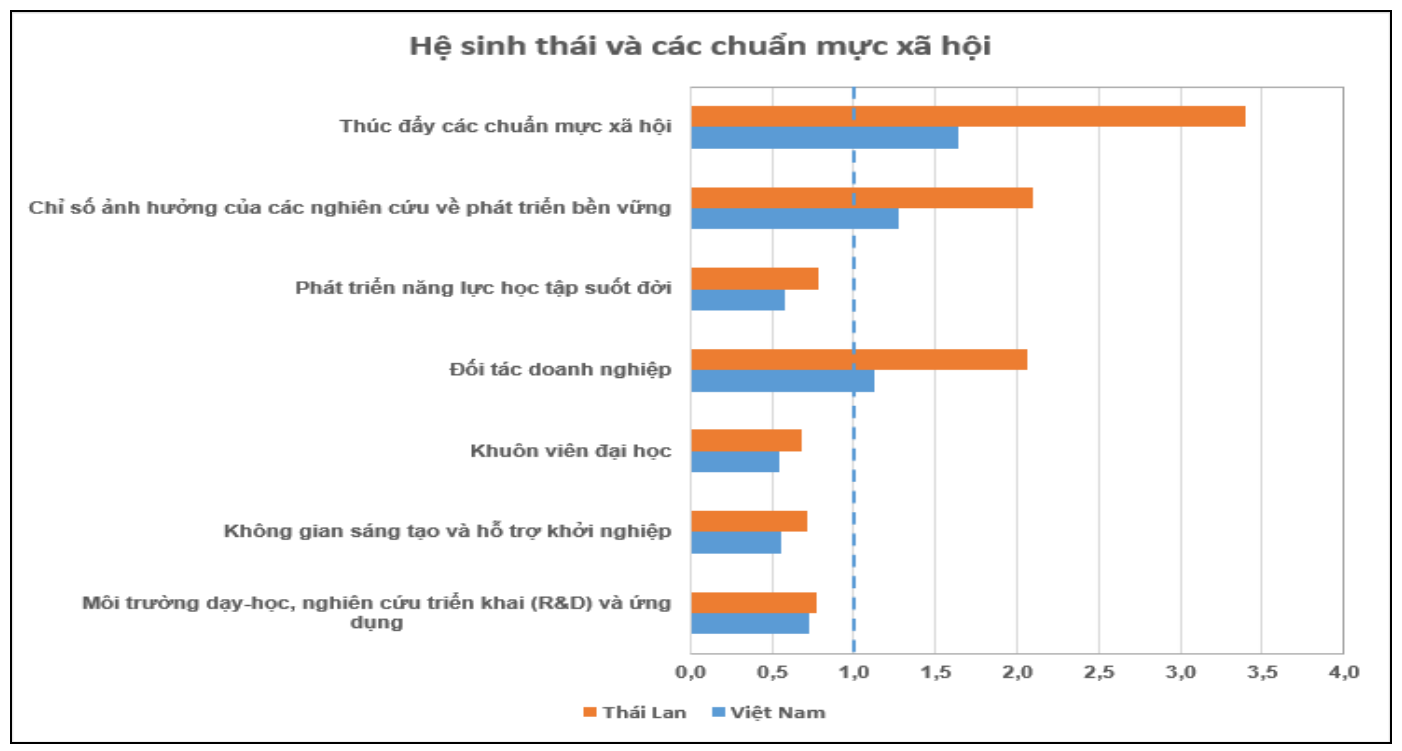

Hình 6. Kết quả đánh giá đã được chuẩn hoá cho các tiêu chí trong nhóm tiêu chuẩn về Hệ sinh thái đại học và các chuẩn mực đạo đức.

\section{Kết luận}

Nghiên cứu này không chỉ mô tả mô hình đại học ĐMST, mà còn đề xuất mô hình và giải pháp phổ quát để tất cả các nhóm trường đại học (định hướng nghiên cứu và ứng dụng) có thể điều chỉnh và phát triển theo định hướng ĐMST để thích ứng với những thay đổi vô định hiện nay. Mô hình đại học này kết hợp hài hoà tinh thần khởi nghiệp và tư duy ĐMST với các đặc trưng và tác động của hệ sinh thái, tạo điều kiện gia tăng giá trị không chỉ của trường mà cả của cộng đồng, do đó tăng cường năng lực tự chủ và trách nhiệm giải trình của trường đại học.

Với năm đặc trưng giáo dục $\mathrm{CMCN} 4.0$ cốt lõi về tinh thần khởi nghiệp, phương pháp tiếp cận ĐMST, chuyển đổi số, đào tạo cá thể hóa, hệ sinh thái và các chuẩn mực xã hội, hệ thống xếp hạng đối sánh UPM phù hợp để hỗ trợ quản lý chiến lược phát triển và quản lý chất lượng các hoạt động của các trường đại học định hướng ĐMST. Hơn nữa, UPM có thể hướng dẫn các nhiệm vụ mà các cơ sở giáo dục đại học phải thực hiện, các ưu tiên và mục tiêu cần đạt được về sứ mệnh và trách nhiệm của họ.

Qua kết quả phân tích và đánh giá, một số trường đại học công nghệ - kỹ thuật của Việt Nam với bề dày truyền thống đã bắt đầu tiếp cận đến các đặc trưng của đại học ĐMST, tuy nhiên, hầu hết các trường đại học này đều ở thời kỳ đang tập trung vào số lượng công bố quốc tế. Trong lúc đó, đối với các trường đại học của Thái Lan, hầu như văn hoá ĐMST của họ đã được xác lập hơn 10 năm qua. Điều này được thể hiện trong việc xây dựng chiến lược phát triển và sự vượt trội trong các chỉ số: chất lượng tuyển sinh các ngành công nghệ - kỹ thuật; trình độ và chất lượng đội ngũ giảng viên; số lượng bằng sáng chế và giải pháp hữu ích đăng ký trong nước; số lượng doanh nghiệp khởi nghiệp; số lượng đối tác doanh nghiệp; tài nguyên số; triển khai sử dụng công cụ kiểm tra đạo văn; tác động của nghiên cứu đến mục tiêu phát triển bền vững và các hoạt động nêu cao chuẩn mực xã hội.

Đối với chiến lược phát triển trong thời gian tới, trong khi cần chuyển ưu tiên từ số lượng sang chất lượng nghiên cứu khoa học và công bố quốc tế, các trường đại học Việt Nam cần thiết là phải xây dựng và phát triển đầy đủ các chức năng và nhiệm vụ của đại học theo định hướng ĐMST. Đó vừa là mục tiêu, đồng thời là phương thức để phát triển thích ứng với $\mathrm{CMCN}$ 4.0, đáp ứng nhu cầu xã hội và nhờ đó tăng cường năng lực thực hiện quyền tự chủ trong 
mọi hoạt động của mình. Đặc biệt, để có thể áp dụng rộng rãi mô hình đại học ĐMST phổ quát này, Việt Nam không những cần định hình lại quỹ đạo phát triển đất nước theo mô hình dựa trên ĐMST, mà còn phải tập trung thúc đẩy việc ứng dụng các công nghệ tiên tiến hiện có và khuyến khích đổi mới sáng tạo phi $R \& D$ thay vì chỉ chú trọng vào hoạt động $R \& D$ như hiện nay.

\section{Tài liệu tham khảo}

[1] W. N. Gleason, Edited, Higher Education in the Era of the Fourth Industrial Revolotion, Palgrave Macmillan, Singapore, 2018.

[2] J. G. Wissema, Towards the Third Generation University - Managing the University in Transition, Edward Elgar, Cheltenham, United Kingdom, 2009.

[3] Ronald Barnett, The Ecological University - A Feasible Utopia, Routledge, London and New York, 2018.

[4] N. H. Duc, N. H. T. Chung, N. X. Huy, M. T. Q. Lan, T. B. Lieu, H. Q. Thuy, N. Loc, Higher Education 4.0: Characteristics and Criteria, VNU Journal of Science: Policy and Management Studies, Vol. 34, No. 4, 2018, pp. 1-28, http://doi.org/10.25073/2588-1116/vnupam.4160.

[5] N. H. T. Chung, T. V. Hai, V. T. M. Anh, N. X. Huy, T. T. T. Hien, N. H. DucSMARTI University Model and Performance Benchmarking System UPM, VNU Journal of Science: Policy and Management Studies, Vol. 36, No. 1, 2020, pp. 28-43, https://doi.org/10.25073/2588-1116/vnupam.4212.

[6] J. Dewar, University 4.0: Redefining the Role of Universities in the Modern Era,

https://www.thehighereducationreview.com/magazi ne/university-40-redefining-the-role-of-universities- in-the-modern-era SUPG758722027.html/, 2021 (accessed on: September 22 ${ }^{\text {nd }}, 2021$ ).

[7] University Performance Metrics, https://upm.vn/, 2021 (accessed on: September 22 ${ }^{\text {nd }}, 2021$ ).

[8] H. J. Etzkowitz, Innovation Lodestar: The Entrepreneurial University in a Stellar Knowledge Firmament, Technological Forecasting and Social Change, Online 01 June 2016, 2016.

[9] Malaysia, Framing Malaysian Higher Education Future Proof Talents, Ministry of Higher Education Malaysia, 2018a.

[10] UK Innovation Strategy: Leading the Future by Creating it,

https://www.gov.uk/government/publications/ukinnovation-strategy-leading-the-future-by-creatingit /, 2021 (accessed on: September 22 ${ }^{\text {nd }}, 2021$ ).

[11] R. Hagen, Globalization, University Transformation and Economic Regeneration, A UK Case Study of Public/private Sector Partnership, The International Journal of Public Sector Management, Vol. 15, No. 3, 2002, pp. 204-218.

[12] D. A. Kirby, M. Guerrero, D. Urbano, Making Universities More Entrepreneurial: Development of a Model, Vol. 28, No. 3, 2011, pp. 302-316, https://doi.org/10.1002/cjas.220,

[13] D. Smith, B. R. Clark, Creating Entrepreneurial Universities: Organizational Pathways of Transformation, Higher Education, Vol 38, 1998, pp. 373-374, https://doi.org/10.1023/A:1003771309048.

[14] UNESCO-Education Sector, Classroom Revolution Through SMART Education in the Republic of Korea - Case Study by the UNESCO - Fazheng Project on Best Practices in Mobile Learning, UNESCO, 2019.

[15] N. H. Duc, H. Q. Thuy, P. B. Son, T. T. Hieu, T. Q. Cuong, Conceptual and Rating Model of the V-SMARTH Smart University, VNU Journal of Science: Education Research, Vol. 36, No. 2, 2020, pp. 1-28, https://doi.org/10.25073/2588-1159/vnuer.4400. 